\title{
ANALISI PENGARUH SISA KLOR YANG OPTIMUM DALAM MENGHILANGKAN KANDUNGAN BAKTERI E.COLI DAN FECAL COLI FORM
}

\author{
Irfan Arief \\ Jurusan Teknik Lingkungan, Fakultas Arsitektur Lanskap dan Teknologi Lingkungan, \\ Universitas Trisakti, Jakarta, Indonesia \\ Email korespondensi: irfan08214034@std.trisakti.ac.id
}

\begin{abstract}
ABSTRAK
Penyediaan air minum bagi masyarakat harus memenuhi syarat kualitas yang berupa syarat fisik, kimia, dan bakteriologis. Penggunaan suatu desinfektan kaporit dan gas klor mempengaruhi kualitas air minum pada suatu instalasi. Metode pengambilan contoh uji dilakukan menggunakan cross sectional yaitu variabel independen dan dependen dikumpulkan secara bersamaan dan pengukuran dilakukan pada saat penelitian. Hasil penuisan menggambarkan jumlah nilai sisa klor terhadap kandungan bakteri e.coli berpengaruh. Zat klorin perlu ditambahkan sebagai desinfektan pada suatu instalasi. Oleh karena itu diperlukan studi lebih lanjut mengetahui besar pengaruh sisa klor terhadap kandungan bakteri E.Coli, sehingga dapat direkomendasikan untuk penggunaan yang lebih efisien.
\end{abstract}

Kata Kunci: Air minum; Desinfeksi; Sisa Klor

\section{PENDAHULUAN}

Air merupakan sumber daya alam yang banyak digunakan untuk kebutuhan sehari-hari mahluk hidup. Karena butuhnya manusia terhadap air sangatlah banyak sehingga perlu dikembangkan dan dikelola untuk dimanfaatkan secara efisien dan berkelanjutan. Suatu sistem yang terdapat pada Instalasi Pengolahan Air (IPA) dapat dilihat dari 3 hal, yaitu kualitas, kuantitas dan kontinuitas air yang diproduksi. Dimana ketiga kondisi tersebut dapat dicapai bila persayaratan kondisi teknis maupun non teknis dapat terpenuhi dengan baik. Salah satu aspek yang perlu diawasi dari suatu pengolahan air minum adalah kualitas airnya yang harus memenuhi syarat, baik meliputi fisik, kimia, dan mikrobiologi. Mengacu pada Peraturan Menteri Kesehatan Nomor 32 Tahun 2017, yang berkaitan dengan standar kualitas kesehatan lingkungan dan air, beberapa parameter fisik, kimia, dan biologis dinyatakan yang mencakup standar yang harus diperoleh agar air dapat digunakan dengan aman oleh manusia. Warna, kekeruhan, total coliform, nitrit dan nitrat adalah beberapa parameter yang standarnya ditentukan dalam peraturan

Pengawasan kualitas air minum secara kimiawi termasuk salah satu upaya sanitasi yang dilakukan. Salah satunya adalah pemberian senyawa kimia berupa senyawa desinfektan klor berupa kaporit $\left(\mathrm{Ca}\left(\mathrm{OCl}_{2}\right)\right)$ yang berfungsi untuk mereduksi zat organik, mengoksidasi logam. Namun kualitas air terkait dengan sisa klorin (desinfektan) dan ketika memasuki jaringan distribusi masih belum dapat perhatian yang baik pada saat perencanaan maupun saat operasional. Sisa klorin yang efektif merupakan salah satu aspek yang sangat penting untuk menjamin kualitas air yang mencapai konsumen. Dengan kualitas yang baik akan berdampak langsung terhadap penghilangan kandungan mikroorganisme pada air. Tujuan penulisan ini ialah untuk mengetahui konsentrasi sisa klor yang mana yang dapat membunuh mikroorganisme secara keseluruhan

\section{TINJAUAN PUSTAKA}

Kualitas air harus berdasarkan persyaratan kualitas air bersih dan air minum yang telah ditetapkan oleh Keputusan Menteri Kesehatan Republik Indonesia Nomor 492/MENKES/PER/IV/2010 mengenai Persyaratan Air Minum salah satunya pada syarat biologi. Syarat biologi digunakan untuk mencegah bakteri berbahaya yang berada di dalam air 
baku. Parameter biologi yang harus memenuhi standar persyaratan berupa total bakteri koliform dan E. Coli. Escherichia coli merupakan bakteri batang gram negatif, tidak berspora dan motil berbentuk flagel peritrik, Berdasarkan Permenkes No. 492 tahun 2010 tentang persyaratan kualitas air minum menyebutkan bahwa kandungan bakteri Escherecia Coli dalam air minum yaitu 0/100 ml. Oleh sebab itu Air bersih dan air minum tidak boleh melebihi persyaratan yang telah ditentukan apabila dalam air minum dan air bersih sudah tercemar bakteri Escherecia Coli maupun Total Coliform yang melebihi persyaratan maka akan menyebabkan beberapa penyakit pencernaan dan penyakit lainnya seperti penyakit kolera, diare, dan tifus. Kualitas mikrobiologis air ditentukan berdasarkan ada atau tidaknya bakteri E. coli di dalam air dan jumlah bakteri tersebut di dalamnya.

\section{Desinfeksi}

Desinfeksi merupakan suatu proses yang mendestruksi sebagian besar mikroorganisme yang bersifat patogenik pada suatu instrument dengan menggunakan cara fisik (pemanasan) maupun cara kimiawi (penambahan bahan kimia) (McCarthy and Smith,1974). Desinfektan merupakan bahan kimia yang digunakan untuk mencegah terjadinya infeksi dengan membunuh jasad renik (bakterisid), terutama pada benda mati. Proses desinfeksi dapat menghilangkan 60\% 90\% jasad renik. Desinfektan digunakan untuk sanitasi baik di rumah tangga, laboratorium, dan rumah sakit (Shaffer, 1965; Larson, 2013). Agar berfungsi optimal, desinfektan harus mempunyai waktu kontak dengan air yang diproses secara tepat. Waktu kontak ditentukan sebagai waktu tersedia untuk interaksi antara klor dengan bahan pereduksi klor di dalam air.

Tabel 1. Hasil Perbandingan Sisa Klor Terhadap kandungan Bakteri E.Coli dan Coliform

\begin{tabular}{|c|c|c|}
\hline Judul Paper, tahun & Penulis & Hasil Penelitian \\
\hline $\begin{array}{l}\text { Kadar sisa chlor dan kandungan } \\
\text { bakteri E.Coli PDAM Tirta Moedal } \\
\text { Semarang, } 2013\end{array}$ & $\begin{array}{l}\text { Duta Andhika, Trijoko, dan Yusniar } \\
\text { Hanani }\end{array}$ & $\begin{array}{ll}\text { - } & \text { Kandungan bakteri E.Coli } \\
\text { sebelum pengolahan } \\
\text { sebesar } 922,56 / 100 \mathrm{ml} \\
\text { sampel air. Sesudah } \\
\text { pengolahan 7,28 per } 100 \mathrm{ml} \\
\text { sampel air. } \\
\text { Kadar sisa khlor sesudah } \\
\text { pengolahan sebesar } 0,13 \\
\text { mg/L }\end{array}$ \\
\hline $\begin{array}{l}\text { Kadar Sisa Chlor Terhadap Niai } \\
\text { NPM Coli Form PDAM Kabupaten } \\
\text { Hulu Sungai Utara, } 2016\end{array}$ & $\begin{array}{l}\text { Muhammad Rifani, Munawar } \\
\text { Raharja, dan Isnawati }\end{array}$ & $\begin{array}{l}\text { Kandungan bakteri E.Coli } \\
\text { sebelum pengolahan lebih } \\
\text { dari } 1898 / 1000 \mathrm{ml} \text { sampel } \\
\text { air. Sesudah pengolahan } \\
\text { 0/1000 ml sampel air. } \\
\text { - Kadar sisa khlor sesudah } \\
\text { pengolahan sebesar } 1-1,5 \\
\text { mg/L } \\
\end{array}$ \\
\hline $\begin{array}{l}\text { Pengaruh Residual Klorin Terhadap } \\
\text { Kualitas Mikrobiologi Pada Jaringan } \\
\text { Distribusi Air Bersih IPA Cilandak, } \\
2012\end{array}$ & $\begin{array}{l}\text { Azhar Fuadi, Firdaus Ali dan Irma } \\
\text { Gusniani }\end{array}$ & $\begin{array}{l}\text { - } \quad \text { Kandungan bakteri E.Coli } \\
\text { sebelum pengolahan } \\
\text { 2384968/1000 ml sampel } \\
\text { air. Sesudah pengolahan } \\
\text { 0/1000 ml sampel air. } \\
\text { Kadar sisa khlor sesudah } \\
\text { pengolahan sebesar } 0,8 \\
\text { mg/L } \\
\end{array}$ \\
\hline $\begin{array}{l}\text { Hubungan Jarak Tempuh Dengan } \\
\text { Kadar sisa klor dan MPN Coliform } \\
\text { di PDAM Resrvoir Medini Kudus, } \\
2018\end{array}$ & $\begin{array}{l}\text { Noor Zahrotul M, Noor Jazuli, dan } \\
\text { Tri Joko }\end{array}$ & $\begin{array}{l}\text { Kandungan bakteri E.Coli } \\
\text { sebelum pengolahan } \\
\text { 250/1000 ml sampel air. } \\
\text { Sesudah pengolahan 0/1000 } \\
\text { ml sampel air. } \\
\text { - } \quad \text { Kadar sisa khlor sesudah } \\
\text { pengolahan sebesar } 0,22- \\
0,8 \mathrm{mg} / \mathrm{L}\end{array}$ \\
\hline
\end{tabular}


Jumlah sisa klor terhadap kandungan bakteri e.coli sangatlah berpengaruh. Perlunya penambahan zat klorin sebagai desinfektan terhadap pengolahan air dengan kadar yang sesuai dengan baku mutu. Berdasarkan penulisan di atas dapat disimpulkan bahwa dengan sisa klor di bawah 0,2 $\mathrm{mg} / \mathrm{l}$ masih belum bisa menghilangkan bakteri e.coli secara keseluruhan/

\section{UCAPAN TERIMA KASIH}

Terima kasih kepada dosen pembimbing yang telah memberi arahan dalam penulisan karya ilmiah ini.

\section{DAFTAR PUSTAKA}

Azhar Fuadi, Firdaus Ali dan Irma Gusniani.2012. Pengaruh Residual Klorin Terhadap Kualitas Mikrobiologi Pada Jaringan Distribusi Air Bersih IPA Cilandak. Depok: Universitas Indonesia. 106-FT.TL/SKRIP/7/2012.

Bambang Suharto, Liliya Dewi, Aulia Nur, Tyas Roro. 2019. The Study of Water Quality Status in The Ngebrong River with Physical and Chemical Parameters in The Tawangsari Barat Region, Pujon District, Malang Regency. Malang: Universitas Brawijaya, Departement of Environmental Engineering. DOI : http://dx.doi.org/10.25105/urbanenvirotech.v2i2.4361

Duta Andhika, Trijoko, dan Yusniar Hanani. 2013. Kadar sisa chlor dan kandungan bakteri E.Coli PDAM Tirta Moedal Semarang. . Jurnal Kesehatan Masyarakat (e-Journal) Vol. 2, No.2 (http://ejournal1.undip.ac.id/index.php./jkm)

McCarthy, J. J. and Smith, C.H. 1974. The Use of Ozone in Advanced Wastewater Treatment. Journal of AWWA. 66(12):718

Muhammad Rifani, Munawar Raharja, dan Isnawati. 2016. Kadar Sisa Chlor Terhadap Niai NPM Coli Form PDAM Kabupaten Hulu Sungai Utara. Jurnal Kesehatan Lingkungan Vol.13, No.2.

Noor Zahrotul M, Noor Jazuli, dan Tri Joko. 2018. Hubungan Jarak Tempuh Dengan Kadar sisa klor dan MPN Coliform di PDAM Resrvoir Medini Kudus. Jurnal Kesehatan Masyarakat (e-Journal) Vol. 6, No.6 (ISSN: 2356-3346). http://ejournal3.undip.ac.id/index.php./jkm)

Rijal Hakiki dan Temmy Wikaningrun. 2019. The Prospect of Digitally Enhance Colorimetry as an Analytical Method for Water Quality Determination. Cikarang: President University, Departement of Environmental Engineering. 2(2): 146-163. DOI: http://dx.doi.org/10.25105/urbanenvirotech.v0i0.4362

Shaffer, J.G. (1965). The Role of Laboratory in Infection Control in the Hospital. Arbor: University of Michigan, School of Pulbic health. Hal. 354, 357. 